\title{
Dichotic Listening before and after Fluoxetine Treatment for Major Depression: Relations of Laterality to Therapeutic Response
}

\author{
Gerard E. Bruder, Ph.D., Michael W. Otto, Ph.D., Patrick J. McGrath, M.D.,
} Jonathan W. Stewart, M.D., Maurizio Fava, M.D., Jerrold F. Rosenbaum, M.D., and Frederic M. Quitkin, M.D.

Despite the wide variance in therapeutic response to antidepressants, there are few clinical or biological predictors of treatment outcome. Studies have suggested the possible value of dichotic listening measures of perceptual asymmetry (PA) as predictors of treatment response. This study examined the relation between outcome of fluoxetine treatment and performance on verbal and nonverbal dichotic tests. As part of a multisite study, 86 outpatients with major depression were tested on dichotic fused-words and complex-tones tests both before and during treatment. Fluoxetine responders differed from nonresponders in having greater right-ear (left-hemisphere) advantage for
KEY WORDS: Laterality; Dichotic listening tests; Depression; Fluoxetine; Antidepressive agents; Treatment outcome

Despite the abundance of medications for depressive disorders, clinicians lack the methodology to determine which treatment will benefit a given patient. The search for predictors of treatment response for patients with

From the Department of Biopsychology (GEB) and the Depression Evaluation Service (PJM, JWS, FMQ), New York State Psychiatric Institute; the Department of Psychiatry (GEB, PJM, JWS, FMQ), College of Physicians and Surgeons, Columbia University and the Behavior Therapy and Clinical Psychopharmacology Units (MWO, MF, JFR), Massachusetts General Hospital and Harvard Medical School, Boston.

Address correspondence to: Dr. Gerard E. Bruder, Department of Biopsychology, New York State Psychiatric Institute, 722 W168th Street, New York, NY 10032.

Received May 1, 1995; revised August 30, 1995; accepted September 21, 1995 . dichotic words and less left-ear (right-hemisphere) advantage for complex tones. There was no change in PA during fluoxetine treatment, which indicates that $P A$ differences between treatment responders and nonresponders are stable (trait) characteristics. An aggregate, characteristic PA measure was the best predictor of responder status in a logistic regression analysis. Findings from two clinical centers support the hypothesis that a characteristic tendency for relatively greater left- than right-hemispheric activation during dichotic listening is associated with better outcome of fluoxetine treatment.

[Neuropsychopharmacology 15:171-179, 1996]

major depression has most frequently targeted clinical factors (Joyce and Paykel 1989; Sotsky et al. 1991) or biochemical measures (Mooney et al. 1991; Ribeiro et al. 1993) . Relatively little attention has been devoted to the study of neuropsychological or cognitive predictors of treatment response.

Visuospatial performance deficits on neuropsychological tests (Flor-Henry 1976) and hemifield-specific deficits on visual half-field tests (Liotti et al. 1991; Bruder et al. 1992) have suggested that cognitive abnormalities in depression are related more to right- than left-hemisphere dysfunction. On the other hand, evidence of left frontal inactivation has been found for depressed patients in a resting state when using quantitative EEG and neuroimaging techniques (Baxter et al. 1989; Davidson and Tomarken 1989; Henriques and Davidson 1991), and major depression following stroke was associated with lesions of the left frontal region (Robin- 
son and Szetela 1981; Robinson et al. 1984). Hemispheric asymmetries in the function or structure of the brain appear to play an important role in mood disorders, and therefore, investigating their possible value as predictors of treatment outcome would be in order.

One easy-to-use method for assessing hemispheric asymmetry of function is dichotic listening. In dichotic tests, different stimuli (e.g., words or syllables) are simultaneously presented to the left and right ears, and differences in performance between the ears provide a measure of perceptual asymmetry (PA). Ear advantages on dichotic tests are thought to represent the advantage of the contralateral hemisphere for processing verbal or nonverbal stimuli. Thus, the Fused Rhymed Words Test yields a right-ear advantage in normal adults having left-hemisphere dominance for language (Wexler and Halwes 1983; Zatorre 1989). In contrast, the Complex Tone Test, which provides a measure of right-hemisphere dominance for pitch discrimination, yields a leftear advantage in normal adults (Sidtis 1981; Tenke et al. 1993).

Studies have found abnormal dichotic listening in depressed patients, with the most consistent finding being a reduction in left-ear (right-hemisphere) advantage for nonverbal dichotic tests (Bruder et al. 1981; Johnson and Crockett 1982; Overby et al. 1989). Individual differences in PA among depressed patients have also been related to their diagnostic subtype (Bruder et al. 1989; Bruder 1995), biochemical measures [i.e., serum testosterone (Wexler et al. 1989) or plasma cortisol (Otto et al. 1991)], and outcome of treatment with antidepressants (Bruder et al. 1990; Otto et al. 1991). This raises the possibility that individual differences in hemispheric asymmetry might ultimately be of some value in identifying subtypes of depression with distinctive pathophysiology and response to treatment.

Although examining the association between PA and treatment response is a relatively new endeavor, two studies reported promising findings. Bruder et al. (1990) found that depressed outpatients who responded to treatment with a tricyclic antidepressant failed to show a left-ear (right-hemisphere) advantage for a nonverbal dichotic listening test, whereas treatment nonresponders showed the normal left-ear (right-hemisphere) advantage. In a separate study, Otto et al. (1991) found that PA as assessed by a verbal dichotic listening task, predicted response to treatment with oral s-adenosyl-1-methionine (SAMe) or placebo. Patients with a stronger rightear (left-hemisphere) advantage improved to a greater degree. Of particular interest in these two studies is the consistency in the direction of PA findings. On both verbal and nonverbal dichotic tests, patients with the largest relative favoring of right ear over left ear performance experienced the greatest clinical improvement.

One interpretation of these findings is that treatment responders differ from nonresponders in their "charac- teristic" PA, a term used to describe individual differences in PA that are stable across verbal and nonverbal laterality tasks (Levy et al. 1983). Levy and associates hypothesized that characteristic PA reflects a tendency toward relatively greater left- or right-hemisphere activation regardless of the task. Thus, between-subject differences in PA are viewed as being due more to taskindependent differences in characteristic activation asymmetry than to hemispheric specialization for verbal or nonverbal processing.

The differences in PA between treatment responders and nonresponders in the Bruder et al. and Otto et al. studies suggested the following hypothesis. A characteristic PA reflecting relative favoring of left- over righthemisphere activation is associated with better outcome of treatment with antidepressants. This hypothesis was evaluated in the present study by comparing the performance of treatment responders and nonresponders on the Fused Rhymed Words Test (Wexler and Halwes 1983) and the Complex Tone Test (Sidtis 1981). Groups were compared not only on PA measures for each test but also on a combined measure of characteristic PA, which was obtained by averaging the standardized scores for the verbal and nonverbal dichotic test.

This study was conducted as part of a multisite study of the long-term efficacy of fluoxetine (Prozac) treatment for major depression, in which the same dichotic listening tests were administered to depressed patients at two clinical centers and standardized treatment and assessment protocols were used at each site. This provided a replication across treatment centers, which is particularly important given the lack of replication of many findings concerning predictors of treatment response (Joyce and Paykel 1989; Stosky et al. 1991).

The study was also designed to compare dichotic listening performance across pre- and posttreatment sessions. Bruder et al. (1990) found that PA in depressed patients on dichotic tests did not change significantly following treatment with a tricyclic antidepressant, supporting the hypothesis that PA represents a stable state-independent characteristic. Nonetheless, contradictory data exist (Johnson and Crockett 1982), and one aim was therefore to examine the stability of PA scores with fluoxetine treatment and clinical improvement.

\section{METHODS}

\section{Subjects}

The subjects were outpatients at New York State Psychiatric Institute (NYSPI) or Massachusetts General Hospital $(\mathrm{MGH})$. Written informed consent was obtained from all patients after the testing procedures had been fully explained. Eligible patients met DSM-III-R criteria 
for major depressive disorder as determined by the Structured Clinical Interview for DSM-III-R Patient Edition (SCID-P) (Spitzer et al. 1988) and had a score of at least 16 on a modified 17-item Hamilton Rating Scale for Depression (HAM-D-17*) (Hamilton 1960) at both an initial screening visit and a baseline visit one week later. A modified HAM-D-17* score was calculated from a combination of 17 of the 28 items on the scale. Items $1-3,7-11,13-15$, and 17 (from the unmodified scale) were used for all patients. To these were added either items 4, 5, or 6 (insomnia items) and 12 and 16 (anorexia/weight loss items) or items 22-26 (hypersomnia/ hyperphagia items) depending on whether the patient's overall neurovegetative ratings were greater for positive symptoms (insomnia/anorexia) or reversed symptoms (hypersomnia/hyperphagia). This method of assessing depression severity allows an emphasis on neurovegetative symptoms or reverse symptoms depending on the predominant symptoms of each patient (Fava et al. 1993). In all cases, assessments were completed by research psychiatrists and psychologists experienced in the assessment and treatment of depression and trained in the use of the structured assessment instruments. We have found excellent inter-rater reliability for the 28-item HAM-D scale (intraclass correlation = 0.92).

Patients were excluded from the treatment study for any of the following reasons: serious suicidal risk, serious medical illness, pregnancy, breastfeeding, history of seizure disorder, organic mental disorders, substance use disorders (including alcohol abuse) within the last year, schizophrenia, delusional disorder, psychotic disorders not elsewhere classified, mood-congruent or mood-incongruent psychosis, bipolar disorder (not including bipolar disorder not otherwise specified), antisocial personality disorder, current use of psychotropic drugs, history of multiple adverse drug reactions or allergy to fluoxetine, and clinical or laboratory evidence of hypothyroidism. In addition, patients were excluded from participation in dichotic tests if they had a hearing loss greater than $30 \mathrm{~dB}$ in either ear at $500,1,000$ or $2,000 \mathrm{~Hz}$.

A total of 46 patients at NYSPI and 40 patients at MGH were tested on both verbal and nonverbal dichotic listening tests during a drug-free period (between the screening and baseline visits) and during fluoxetine treatment (after 8 to 12 weeks of treatment). Patients were antidepressant-free for at least 2 weeks prior to the screening visit. Following the baseline visit, each patient received 12 weeks of treatment with a fixed dose of fluoxetine ( $20 \mathrm{mg}$ /day). Patients were classified as treatment responders if they had a HAM-D-17* score of 7 or less and no longer met DSM-III-R criteria for major depression for 3 consecutive weeks. The study period was extended for up to 2 weeks of additional treatment if the patient was close to meeting criteria for response at the end of the 12th week of treatment. Two patients at NYSPI were not included in this report because they were dropped from the treatment protocol prior to the end of the 12th week, and two patients at MGH were not included because one discontinued treatment before the 12th week, while the other met remission criteria for 3 weeks but relapsed during the week of the retest.

Table 1 gives the characteristics of the patients at NYSPI and MGH who were classified as treatment responders or nonresponders. There were 32 responders and 14 nonresponders at NYSPI, and 26 responders and 14 nonresponders at MGH. These groups did not differ significantly in gender, age, or education level. There was no significant difference between the responder and nonresponder groups in handedness laterality quotients (LQs) on the Edinburgh Handedness Inventory (Oldfield 1971), although the MGH patients were more strongly right handed than the NYSPI patients $(F=$ $4.60, \mathrm{df}=1,81, p<.05)$. There was no difference between the treatment responder and nonresponder groups or between the NYSPI and MGH sites in pretreatment ratings of severity on the HAM-D-17* scale. Patients in each group were moderately depressed before treatment. Following treatment, responders had significantly lower HAM-D-17* scores than nonresponders at each site $(F=183.10, \mathrm{df}=1,81, \mathrm{p}<.0001)$. The number of prior episodes of depression did not differ significantly between treatment responders $(M=$ $3.3, \mathrm{SD}=7.0)$ and nonresponders $(\mathrm{M}=3.5, \mathrm{SD}=9.5)$. A rating of the duration of symptoms in the current episode, where $1=1-3$ months, $2=3-6$ months, $3=6-12$ months, $4=12-24$ months, and $5=>24$ months, did not differ between responders $(M=4, \mathrm{SD}=1.3)$ and nonresponders $(M=3.9, \mathrm{SD}=1.2)$ either.

\section{Procedures}

Patients were tested on a dichotic fused-words and a complex-tones test. The order of these tests was counterbalanced across patients. A brief description of each test is given.

Dichotic Words Test. The Fused Rhymed Words Test (Wexler and Halwes 1983) consists of 15 different single-syllable word pairs in which each member of every pair differs from the other only in the initial consonant (e.g., coat, goat). All words begin with one of six stop consonants (b, d, p, t, g, k) and are natural-speechspoken by a male voice. When presented dichotically, the members of each pair fuse into a single auditory image. Subjects indicate what word they heard by marking a line through it on a prepared answer sheet that has four possible responses, both members of the dichotic pair and two other words differing from the dichotic stimuli only in the initial consonant. Four 30-item 
Table 1. Subject Characteristics

\begin{tabular}{|c|c|c|c|c|c|}
\hline & & \multicolumn{2}{|c|}{ NYSPI } & \multicolumn{2}{|c|}{ MGH } \\
\hline & & $\begin{array}{c}\text { Responders } \\
(n=32)\end{array}$ & $\begin{array}{l}\text { Nonresponders } \\
\quad(n=14)\end{array}$ & $\begin{array}{l}\text { Responders } \\
\quad(n=26)\end{array}$ & $\begin{array}{c}\text { Nonresponders } \\
\quad(n=14)\end{array}$ \\
\hline \multirow[t]{2}{*}{ Gender } & $\mathrm{F}$ & 21 & 6 & 15 & 9 \\
\hline & $M$ & 11 & 8 & 11 & 5 \\
\hline \multirow[t]{2}{*}{ Age } & $\mathrm{M}$ & 39.9 & 39.1 & 38.7 & 40.4 \\
\hline & SD & 10.2 & 11.4 & 9.8 & 8.2 \\
\hline \multirow[t]{2}{*}{ Education } & $\mathrm{M}$ & 14.6 & 15.7 & 14.6 & 14.3 \\
\hline & SD & 3.4 & 2.7 & 2.7 & 3.2 \\
\hline \multirow{2}{*}{$\begin{array}{l}\text { Handedness } \\
\text { (LQ) }\end{array}$} & $\mathrm{M}$ & 62.6 & 66.6 & $84.5^{a}$ & $91.6^{a, b}$ \\
\hline & SD & 63.4 & 56.5 & 19.7 & 13.4 \\
\hline \multirow{2}{*}{$\begin{array}{l}\text { Pretreatment } \\
\text { HAM-D-17* }\end{array}$} & $\mathrm{M}$ & 18.2 & 18.5 & 20.6 & 21.4 \\
\hline & SD & 2.7 & 1.9 & 3.3 & 3.1 \\
\hline \multirow{2}{*}{$\begin{array}{l}\text { Posttreatment } \\
\text { HAM-D-17* }\end{array}$} & $\mathrm{M}$ & $3.2^{c}$ & 13.6 & 3.8 & $14.1^{d}$ \\
\hline & SD & 2.8 & 4.3 & 2.2 & 4.7 \\
\hline
\end{tabular}

blocks make up the test for a total of 120 trials. The words were presented via a matched pair of TDH-49 headphones at a comfortable level of $75 \mathrm{~dB}$ SPL.

Complex-Tones Test. This test requires subjects to compare the pitch of a binaural complex tone to the pitches of a dichotic pair of complex tones presented 1 second earlier. Subjects point to a response card labeled "Yes" when the probe tone is the same as either member of the previous dichotic pair or to a card labeled "N" when it differs from both. The complex tones are square waves with fundamental frequencies corresponding to the eight notes in the octave between $\mathrm{C} 4$ and $\mathrm{C} 5$. After 16 binaural and 16 dichotic practice trials, subjects were tested on four blocks of 28 trials in which half of the probe tones matched a member of the dichotic pair and half did not.

\section{Data Analysis}

The number of correct responses was computed for right- (R) and left- (L) ear items in the dichotic-words and complex-tones tests. These scores were used to compute a measure of ear advantage for each test [i.e., $\mathrm{PA}=100(\mathrm{R}-\mathrm{L}) /(\mathrm{R}+\mathrm{L})] . \mathrm{A} 2 \times 2 \times 2 \times 2$ analysis of variance (ANOVA) of the PA scores included the factors of group (responder vs. nonresponder), site (NYSPI vs. $\mathrm{MGH}$ ), test (words vs. complex tones), and session (pretreatment vs. posttreatment), with the last two factors being repeated measures. Separate analyses also compared PA scores of treatment responders and nonresponders for each site and each test. In addition, a $2 \times 2 \times$ $2 \times 2$ ANOVA was performed on the absolute accuracy scores for the complex-tones test, with the factors being group, site, ear, and session. This analysis was not performed on data for the fused-words test because accuracy was essentially $100 \%$ correct for the single response given on each trial.

A measure of "characteristic PA" was obtained for each patient by averaging their standardized PA scores on the dichotic-word and tone tests. The standardized PA scores for each test were computed by subtracting the score for each patient from the mean for all patients and dividing this by the standard deviation of scores. The combined index of characteristic PA should reduce task-specific influences on PA and might thereby provide the best prediction of treatment response. The predictive significance of characteristic PA scores relative to the PA scores for each dichotic test was examined with logistic regression analyses. Logistic regression allows for assessment of the significance of multiple quantitative or categorical variables in a linear model predicting a dichotomous outcome variable (Fleiss et al. 1986). The significance of individual predictors of treatment outcome was assessed by the significance of the corresponding beta weight in the logistic regression equation.

\section{RESULTS}

\section{PA Scores}

Figure 1 gives the mean PA scores for treatment responders and nonresponders on the dichotic-words and complex-tones tests. Arrows show the mean right-ear 


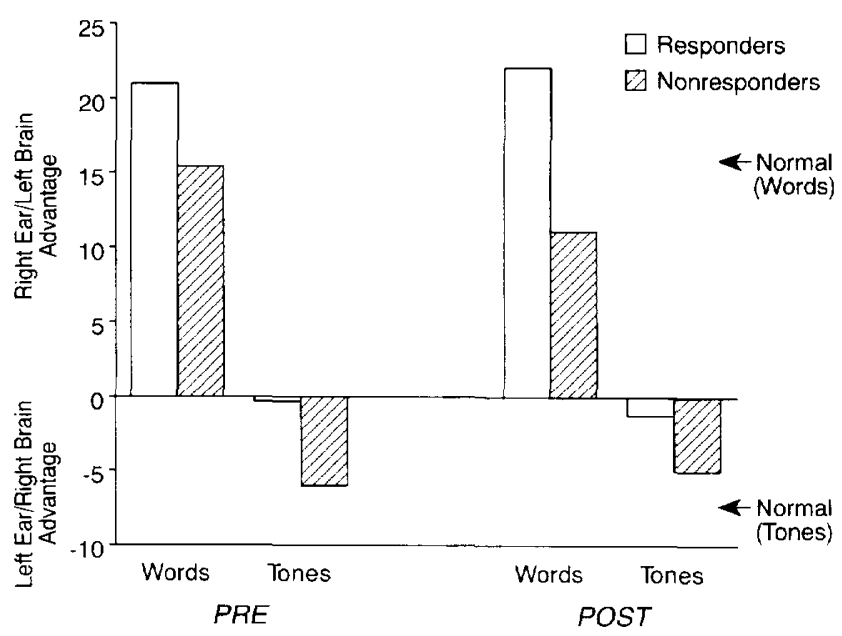

Figure 1. Mean PA scores on dichotic-words and complextones tests for fluoxetine responders (open bars) and nonresponders (hatched bars) during pre- and posttreatment sessions. $\mathrm{PA}=100(\mathrm{R}-\mathrm{L}) /(\mathrm{R}+\mathrm{L})$, where $\mathrm{R}=$ right ear score and $\mathrm{L}=$ left ear score.

(left-hemisphere) advantage for 85 normal adults tested on the fused-words test (Wexler and Goodman 1991) and the mean left-ear (right-hemisphere) advantage for 20 normal adults tested on the complex-tones test (Tenke et al. 1993). As can be seen, treatment nonresponders had essentially the same ear advantages as normal adults on both tests. Treatment responders had a larger right-ear (left-hemisphere) advantage for words than nonresponders. They also differed from nonresponders in showing reduced or no left-ear (right-hemisphere) advantage for complex tones. These group differences were evident in both the pre- and posttreatment sessions.

An ANOVA of the PA scores confirmed the significance of the overall difference in ear advantages between responders and nonresponders $(F=13.98, \mathrm{df}=$ $1,82, p<.001)$ and between tasks $(F=99.74, \mathrm{df}=1,82$, $p<.0001)$. There was no significant change in ear advantages across sessions $(F=0.60, \mathrm{df}=1,82, \mathrm{~ns})$. No significant interactions involving group, test, and session were found, which indicates that the difference in ear advantage between responders and nonresponders was not dependent on the test or session. The only significant interaction was between site and task $(F=$ $13.21, \mathrm{df}=1,82, p<.001$ ), which reflects a difference in ear advantages between the NYSPI and MGH sites for the words test ( $F=13.78, \mathrm{df}=1,82, p<.001)$, but not the complex-tones test. Separate ANOVAs of the PA scores at each site indicated that the difference in ear advantages between treatment responders and nonresponders was significant at the NYSPI site $(F=7.33$, $\mathrm{df}=1,44, p<.01)$ and the MGH site $(F=6.87, \mathrm{df}=1$, $38, p<.02)$. Also, ANOVAs of the PA scores for each test indicated that treatment responders had signifi- cantly larger right-ear (left-hemisphere) advantage for words $(F=7.66, \mathrm{df}=1,82, p<.01)$ and smaller left-ear (right-hemisphere) advantage for complex tones $(F=$ $3.92, \mathrm{df}=1,82, p=.05$ ) than nonresponders.

There was no significant correlation between severity of depression at baseline, as measured by HAM-D$17^{*}$ scores, and baseline ear advantages (PA scores) for either dichotic words $(r=0.13, \mathrm{df}=85, \mathrm{~ns})$ or complex tones $(r=-.18, \mathrm{df}=85, \mathrm{~ns})$. To examine the relationship of baseline ear advantages to a continuous measure of treatment response, pretreatment PA scores for all patients were correlated with the pre- minus posttreatment change in HAM-D-17* scores. Larger rightear (left-hemisphere) advantage for words was associated with greater reduction in depression during treatment with fluoxetine $(r=0.29, \mathrm{df}=84, p<.02)$. There was no significant correlation between PA scores for complex tones and change in HAM-D-17* scores $(r=$ $0.01, \mathrm{df}=84, \mathrm{~ns})$. Correlational analyses also gave no evidence that handedness LQs were related to either treatment response, as measured by HAM-D-17* change scores $(r=-0.03, \mathrm{df}=83, \mathrm{~ns})$, or PA scores for the dichotic-words $(r=0.11, \mathrm{df}=84$, ns) or complextones $(r=0.09, \mathrm{df}=84, \mathrm{~ns})$ tests.

\section{Accuracy Scores for Complex Tones}

If the reduced left-ear advantage for complex tones in treatment responders is due to right-hemisphere dysfunction, one would expect reduced absolute accuracy of dichotic pitch discrimination, and this should be most evident for tones presented to the left ear. As can be seen in Table 2, the smaller left-ear advantage in treatment responders appears to be due to a combination of poorer left-ear accuracy and better right-ear accuracy than for nonresponders. However, an ANOVA of the accuracy scores indicated that there was no significant difference between treatment responders and nonresponders in overall accuracy levels for complex tones $(F=0.05, \mathrm{df}=1,82, \mathrm{~ns})$. This also indicates that the difference in PA between treatment responders and nonresponders could not be due to a difference in overall performance level. There was an interaction between group and ear $(F=3.91, \mathrm{df}=1,82, p=.05)$, which reflects the significantly greater left- than right-ear accuracy in treatment nonresponders $(t=2.30, \mathrm{df}=27, p<$ $.05)$, but not in treatment responders $(t=0.30, \mathrm{df}=57$, $n s)$. The accuracy levels and left-ear advantage for nonresponders are essentially the same as those previously found for normal adults (Tenke et al. 1993). The ANOVA of the accuracy data also revealed a significant session effect $(F=8.92, \mathrm{df}=1,82, p<.005)$, with accuracy being higher in the posttreatment session. A similar increase in accuracy was observed for normal adults who were retested on the Complex Tone Test (Bruder et 
Table 2. Pre- and Posttreatment Mean Accuracy Scores for Complex-Tones Test

\begin{tabular}{|c|c|c|c|c|}
\hline & \multicolumn{2}{|c|}{ Pre } & \multicolumn{2}{|c|}{ Post } \\
\hline & Responders & Nonresponders & Responders & Nonresponders \\
\hline \multicolumn{5}{|l|}{ Left ear } \\
\hline Mean & 79.2 & $82.3^{a}$ & $82.8^{b}$ & $84.9^{n}$ \\
\hline SD & 15.0 & 13.0 & 14.3 & 12.9 \\
\hline \multicolumn{5}{|l|}{ Right ear } \\
\hline Mean & 78.7 & 74.2 & 81.0 & 77.3 \\
\hline SD & 14.6 & 17.1 & 15.2 & 14.9 \\
\hline
\end{tabular}

al. 1994) and is likely to be due to a familiarization or practice effect.

\section{Characteristic PA Scores}

Because differences in PA between responders and nonresponders were not test specific, combining scores for the verbal and nonverbal tests by averaging the standardized scores for each test should more accurately assess this difference than either measure alone. Figure 2 shows the combined index of characteristic PA for individual treatment responders and nonresponders in the pretreatment session. An ANOVA of these scores confirmed the significance of the difference in characteristic PA between responders and nonresponders $(F=8.40$, $\mathrm{df}=1,82, p<.005)$. There was no significant difference in scores between patients at NYSPI (solid circles) and MGH (open circles) and no group-by-site interaction. 'To examine the potential value of characteristic PA scores for predicting outcome of treatment with fluoxetine, the mean score for normal adults (from Wexler and Goodman 1990; Tenke et al. 1993) was used to divide the patients into two subgroups, and a comparison was made of their treatment response rate. Patients with a characteristic PA above the normal mean had a $76 \%$ response rate ( 44 of 58) to fluoxetine, whereas patients with a characteristic PA equal to or less than normal had only a $50 / 50$ chance (14 of 28$)$ of responding to fluoxetine $\left(\chi^{2}\right.$ $(1)=5.79, p<.05)$.

\section{Logistic Regression Analyses}

The PA score for each of the dichotic tests, as well as the index of characteristic PA, were examined as individual and combined predictors in hierarchical logistic regression equations that controlled for baseline depression severity. Characteristic PA was a significant predictor on its own $(t=2.67, \mathrm{df}=84, p<.01)$, and when controlling for baseline depression severity $(t=2.67, \mathrm{df}=83$, $p<.01)$. Patients with a relatively greater right-ear (left-hemisphere) advantage were more likely to re- spond to treatment. Although the task-specific PA scores reached significance either alone or after controlling for baseline depression severity, the characteristic PA score was the most powerful predictor of treatment response in the multiple regression equation. When entered into a hierarchical multiple regression equation, the task-specific PA measures did not exhibit a significant increment in predictability to the characteristic PA measure. In contrast, characteristic PA offered a significant $(p<.05)$ and near-significant $(p<.07)$ increment in predictability when the word and complex-tones PA scores were first entered in the regression equation. The severity of depression at baseline was not itself a signif-

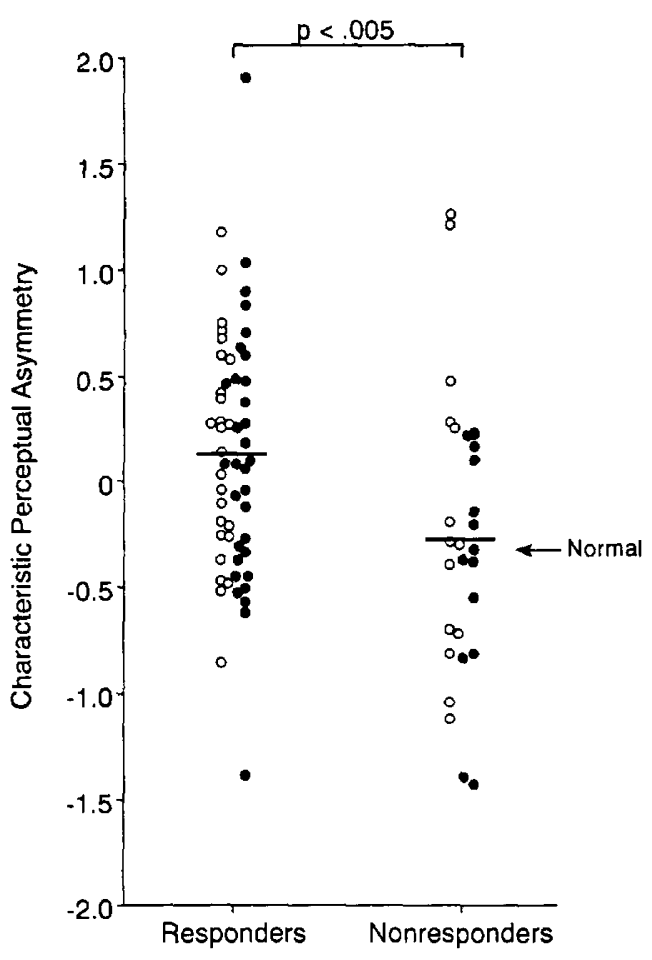

Figure 2. Characteristic PA scores for treatment responders and nonresponders (solid circles, NYSPI; open circles, MGH). The arrow gives the mean score for normal adults. 
icant predictor of treatment response when considered alone or in combination with any other predictor.

\section{DISCUSSION}

Fluoxetine responders differed from nonresponders in having overall greater right-ear advantage for dichotic words and less left-ear advantage for complex tones, which together supports the hypothesis that a relative favoring of left- over right-hemisphere laterality is associated with better outcome of treatment with an antidepressant. The difference in perceptual asymmetry between fluoxetine responders and nonresponders was found for patients at two clinical centers and is therefore unlikely to be the result of an unusual or nonrepresentative clinical sample. These findings are similar to those reported for tricyclic antidepressants, where responders differed from nonresponders in showing no left-ear (right-hemisphere) advantage for complex tones and a trend for greater right-ear (left-hemisphere) advantage for dichotic nonsense syllables (Bruder et al. 1990). Greater right-ear (left-hemisphere) advantage for words was also associated with a more favorable response to treatment in a trial of oral SAM-e or placebo (Otto et al. 1991).

The use of two dichotic listening tests, with both verbal and nonverbal stimuli, permitted an assessment of individual differences on a combined index of characteristic PA. As anticipated, characteristic PA was a more effective predictor of treatment response than either of the task-specific PA scores. It was the only significant predictor in a hierarchical regression equation entering all three PA measures, and it continued to be a significant predictor regardless of whether baseline depression severity was statistically controlled. Patients with a characteristic PA favoring the right ear (left hemisphere) were more likely to respond to fluoxetine treatment. Neither characteristic PA nor treatment response were related to handedness scores.

There was no change in dichotic listening asymmetry during treatment with fluoxetine. This is in accord with findings for tricyclic antidepressants (Bruder et al. 1990) and supports the conclusion that differences in PA between treatment responders and nonresponders represent stable state-independent (trait) characteristics. Similarly, Henriques and Davidson (1990) have found that previously depressed patients in a normothymic state displayed the same pattern of abnormal EEG alpha asymmetries as currently depressed patients. They suggested that regional activation asymmetries in depressed patients are state-independent markers of vulnerability to affective disorders. Taken together, these findings indicate that abnormal dichotic and electrophysiological asymmetries may identify patients who share a common diathesis for a form of depression that responds to antidepressant medication.

The pattern of larger right-ear advantage for words and reduced left-ear advantage for complex tones in fluoxetine responders could stem from right-hemisphere dysfunction, left-hemisphere overactivation, or some combination of both. We have previously found a similar pattern in depressed patients meeting DSM-III criteria for melancholia (Bruder et al. 1989). The larger right-ear advantage in melancholic patients on the dichotic syllable test was due to their abnormally poor left-ear accuracy, which would be consistent with other evidence of right-hemisphere dysfunction found in depressive disorders (Bruder 1995; Flor-Henry 1976; Liotti et al. 1991). In the present study, fluoxetine responders did not differ from nonresponders, or normal adults in prior studies, in accuracy of dichotic pitch discrimination, which provides no support for a right-hemisphere dysfunction interpretation of their difference in PA. An alternative interpretation, consistent with the Levy et al. (1983) concept of "characteristic perceptual asymmetry," is that fluoxetine responders have a relative favoring of left over right hemispheric activation regardless of the perceptual task. More absolute accuracy data are needed to evaluate this "left-hemisphere favoring" hypothesis, particularly for a verbal dichotic listening test.

The hypothesis that fluoxetine responders relatively favor left- over right-hemisphere activation during dichotic listening might appear at odds with evidence that depressive disorders involve inactivation of left frontal regions (Robinson et al. 1984; Baxter et al. 1989; Henriques and Davidson, 1991). However, dichotic listening is likely to involve perceptual processes in more posterior temporoparietal regions (Sidtis and Volpe 1988; Coffey et al. 1989; Davidson and Hugdahl in press). Also, EEG studies have noted an inverse relation between frontal and parietal alpha asymmetries in depression, with less left frontal and right parietal activation in depressed subjects (Davidson et al. 1985; Henriques and Davidson 1990). Moreover, resting EEG alpha asymmetry in posterior temporal and parietal sites predicts performance on verbal and nonverbal cognitive tasks (Davidson and Tomarken 1989; Davidson and Hugdahl in press). The pattern of PA for fluoxetine responders is suggestive of relatively greater activation of left than right temporoparietal regions, which is consistent with the direction of EEG alpha asymmetry for depressed subjects at posterior sites (Davidson et al. 1985; Henriques and Davidson 1990).

Electrophysiological studies showing reciprocal inhibition between frontal and temporoparietal regions (Knight et al. 1980; Tucker et al. 1981) suggest a mechanism that could account for the pattern of PA in fluoxetine responders. Decreased left frontal activation might release the left temporoparietal region from inhibition, resulting in the enhanced left hemispheric processing 
seen in responders. Alternatively, the characteristic PA in treatment responders might reflect reduced activation of a right temporoparietal arousal system, which has been hypothesized to mediate the arousal component of emotion (Levy et al. 1983; Heller 1993). The use of more direct measures of regional hemispheric activity, such as electrophysiological or neuroimaging measures during dichotic tests, would be of particular value in evaluating these alternative hypotheses because they provide topographic data along both left-right and anterior-posterior dimensions.

The potential utility of characteristic PA for predicting outcome of treatment with fluoxetine was evaluated using the normal mean as a cutoff score. This was successful in differentiating subgroups with a significantly different likelihood of responding to fluoxetine. Although the sensitivity (true positive rate) for identifying treatment responders was moderately high $(76 \%)$, the specificity (1-false-positive rate) was relatively low $(50 \%)$. This suggests that the characteristic PA index, in its present form, would be of only modest clinical utility as a predictor of fluoxetine response. However, as will be discussed, there is evidence that characteristic PA can differentiate depressed patients into two subgroups, one with a high likelihood of responding to an antidepressant and one with a lower response rate that is not significantly better than that to a placebo. The findings of this study should encourage further efforts to develop improved behavioral measures of characteristic PA or more direct electrophysiological and neuroimaging measures of hemispheric asymmetry, which could ultimately aid the clinician in identifying depressed patients who would most benefit from antidepressant treatment.

One limitation of this study was the lack of a placebo-treated control group. If patients who improve with placebo treatment show a left hemisphere favoring similar to that of fluoxetine responders, this could suggest that characteristic PA is not an indicator of antidepressant treatment responsiveness but, rather, of a more transient depressive disorder. In a recent study (Stewart et al. 1995) using dichotic-syllable and complex-tones tests, results from tricyclic antidepressants and placebo were compared. Most important, differences in PA between placebo responders and nonresponders were in the opposite direction as those seen for tricyclic antidepressants and fluoxetine. Patients with a characteristic PA score greater than the normal mean had only a $21 \%$ response rate to a placebo, whereas those with a score less than the normal mean had a $39 \%$ response rate to a placebo. Thus, patients with a characteristic PA favoring the left hemisphere (i.e., greater than the normal mean) had a substantially better chance of benefiting from fluoxetine than from a placebo ( $76 \%$ vs. $21 \%$ ). In contrast, patients with a characteristic PA equal to or less than normal had a response rate to fluoxetine that is little better than that to a placebo ( $50 \%$ vs. $39 \%)$. This supports the hypothesis that characteristic PA does have the potential for identifying a subgroup of depressed patients who are likely to derive specific benefit from antidepressant medication (i.e., who show a significant drug vs. placebo difference). A double-blind study that directly compares fluoxetine treatment and placebo is planned to evaluate this hypothesis further.

\section{ACKNOWLEDGMENTS}

Supported in part by grants from Eli Lilly and the National Institute of Mental Health (MH36295). The authors thank Martina Voglmaier, Cornelia Haywood, Jeanine Christiana, Kate Rideout, and Susan Sabatino for their assistance with data acquisition and management; Mary Guardino and the staff of Freedom from Fear for the recruitment of patients; and Donald Klein for his helpful comments on this article.

\section{REFERENCES}

Baxter LR, Schwartz JM, Phelps MS, Mazziotta JC, Guze BH, Selin CE, Gerner RH, Sumida RM (1989): Reduction of prefrontal cortex glucose metabolism common to three types of depression. Arch Gen Psychiatry 46:243-250

Bruder GE (1995): Cerebral laterality and psychopathology: Perceptual and event-related potential asymmetries in affective and schizophrenic disorders. In Davidson $\mathrm{R}$, Hugdahl K (eds), Brain Asymmetry, Cambridge, Massachusetts Institute of Technology Press, pp 661-691

Bruder GE, Sutton S, Berger-Gross P, Quitkin F, Davies S (1981): Lateralized auditory processing in depression: Dichotic click detection. Psychiatry Res 4:253-266

Bruder GE, Quitkin FM, Stewart JW, Martin C, Voglmaier MM, Harrison WM (1989): Cerebral laterality and depression: Differences in perceptual asymmetry among diagnostic subtypes. I Abnorm Psychol 98:177-186

Bruder GE, Stewart JW, Voglmaier MM, Harrison WM, McGrath P, Tricamo E, Quitkin FM (1990): Cerebral laterality and depression: Relations of perceptual asymmetry to outcome of treatment with tricyclic antidepressants. Neuropsychopharmacology 3:1-10

Bruder GE, Stewart JW, Towey JP, Friedman D, Tenke CE, Voglmaier MM, Leite P, Cohen P, Quitkin FM (1992): Abnormal cerebral laterality in bipolar depression: Convergence of behavioral and brain event-related potential findings. Biol Psychiatry 32:33-47

Bruder GE, Schnur DB, Fergeson P, Mukherjee S, Leite P, Sackeim HA (1994): Dichotic-listening measures of brain laterality in mania. J Abnorm Psychol 103:758-766

Coffey CE, Bryden MP, Schroering ES, Wilson WH, Mathew RJ (1989): Regional cerebral blood flow correlates of a dichotic listening task. J Neuropsychiatry 1:46-52

Davidson RJ, Hugdahl K (in press): Baseline asymmetries in brain electrical activity predict dichotic listening performance. Neuropsychology.

Davidson RJ, Tomarken AJ (1989): Laterality and emotion: 
An electrophysiological approach. In F Boller and J Grafman (eds), Handbook of Neuropsychology. Amsterdam, Elsevier, pp 419-441

Davidson RJ, Schaffer CE, Saron C (1985): Effects of lateralized stimulus presentations on the self-report of emotion and EEG asymmetry in depressed and non-depressed subjects. Psychophysiology 22:353-364

Fava M, Rosenbaum JF, Pava JA, McCarthy MK, Steingard RJ, Bouffides E (1993): Anger attacks in unipolar depression, Part I: Clinical correlates and response to fluoxetine treatment. Am J Psychiatry 150(8):1158-1163

Fleiss JL, Williams JBW, Dubro AF (1986): The logistic regression analysis of psychiatric data. I Psychiatr Res 20:145209

Flor-Henry P (1976): Lateralized temporal-limbic dysfunction and psychopathology. Ann N Y Acad Sci 280:777795

Hamilton M (1960) : A rating scale for depression. J Neurol Neurosurg Psychiatry 23:56-62

Heller W (1993): Neuropsychological mechanisms of individual differences in emotion, personality, and arousal. Neuropsychology 7:476-489

Henriques JB, Davidson RJ (1990): Regional brain electrical asymmetries discriminate between previously depressed and healthy control subjects. J Abnorm Psychol 99:22-31

Henriques JB, Davidson RJ (1991): Left frontal hypoactivation in depression. J Abnorm Psychol 100:535-545

Johnson O, Crockett D (1982): Changes in perceptual asymmetries with clinical improvement of depression and schizophrenia. J Abnorm Psychol 91:45-54

Joyce PR, Paykel ES (1989): Predictors of drug response in depression. Arch Gen Psychiatry 46:89-99

Knight RT, Hillyard SA, Woods DL, Neville HJ (1980): The effects of frontal and temporal-parietal lesions on the auditory evoked potentials in man. Electroencephal Clin Neurophysiol 50:112-124

Levy J, Heller W, Banich M, Burton LA (1983): Are variations among right handed individuals in perceptual asymmetries caused by characteristic arousal differences between hemispheres? J Exp Psychol [Hum Percept] 9:329-359

Liotti M, Sava D, Rizzolatti G, Caffarra P (1991): Differential hemispheric asymmetries in depression and anxiety: A reaction-time study. Biol Psychiatry 29:887-899

Mooney JJ, Schatzberg AF, Cole JO, Samson JA, Waternaux C, Gerson B, Pappalardo KM, Schildkraut JJ (1991): Urinary 3-Methoxy-4-hydroxyphenylglycol and the depression-Type score as predictors of differential responses to antidepressants. J Clin Psychopharmacol 11:339-343

Oldfield RC (1971): The assessment and analysis of handedness: The Edinburgh Inventory. Neuropsychologia 9:97113

Otto MW, Fava M, Rosenbaum JF, Murphy CF (1991): Perceptual asymmetry, plasma cortisol, and response to treatment in depressed patients. Biol Psychiatry 30:703710
Overby LA III, Harris AE, Leck MR (1989): Perceptual asymmetry in schizophrenia and affective disorder: Implications from a right hemisphere task. Neuropsychologia $27: 861-870$

Ribeiro SCM, Tandon R, Grunhaus L, Greden JF (1993): The DST as a predictor of outcome in depression: A metaanalysis. Am J Psychiatry 150:1618-1629

Robinson RG, Szetela B (1981): Mood change following left hemisphere brain injury. Ann Neuro1 9:447-453

Robinson RG, Kubos KL, Starr LB, Rao K, Price TR (1984): Mood disorders in stroke patients. Importance of location. Brain 107:81-93

Sidtis JJ (1981): The complex tone test: Implications for the assessment of auditory laterality effects. Neuropsychologia 19:103-112

Sidtis JJ, Volpe BT (1988): Selective loss of complex-pitch or speech discrimination after unilateral cerebral lesion. Brain Lang 34: 235-245

Sotsky SM, Glass DR, Shea MT, Pilkonis PA, Collins JF, Elkin I, Watkins JT, Imber SD, Leber WR, Moyer J, Oliveri ME (1991): Patient predictors of response to psychotherapy and pharmacotherapy: Findings in the NIMH treatment of depression collaborative research program. Am J Psychiatry 148(8):997-1008

Spitzer RL, Williams JB, Gibbon M, First MB (1988): Structured Clinical Interview for DSM III-R-Upjohn VersionRevised (SCID-UP-R) (8/3/88 Version). Biometrics Research Department, New York State Psychiatric Institute

Stewart JW, Bruder GE, Quitkin FM, McGrath P (1995): Perceptual asymmetry predicts differential response to SSRI, TCA and placebo. Paper presented at the NCDEU Annual Meeting: Orlando, Florida

Tenke CE, Bruder GE, Towey JP, Leite P, Sidtis JJ (1993): Correspondence between brain ERP and behavioral asymmetries in a dichotic complex tone test. Psychophysiology 30:62-70

Tucker DM, Stenslie CE, Roth RS, Shearer SL (1981): Right frontal lobe activation and right hemisphere performance decrement during a depressed mood. Arch Gen Psychiatry 38:169-174

Wexler BE, Goodman WK (1991) : Cerebral laterality, perception of emotion, and treatment response in obsessivecompulsive disorder. Biol Psychiatry 29:900-908

Wexler BE, Halwes T (1983): Increasing the power of dichotic methods: The fused rhymed words test. Neuropsychologia 21:59-66

Wexler BE, Mason JW, Giller EL (1989): Possible subtypes of affective disorders suggested by differences in cerebral laterality and testosterone: A preliminary report. Arch Gen Psychiatry 46:429-433

Zatorre RJ (1989): Perceptual asymmetry on the dichotic fused words test and cerebral speech lateralization determined by the carotid sodium amytal test. Neuropsychologia 27:1207-1219 